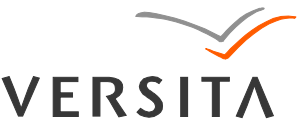

GEOCHRONOMETRIA 40(3) 2013: 153-164

DOI 10.2478/s13386-013-0107-8

Available online at

www.springerlink.com

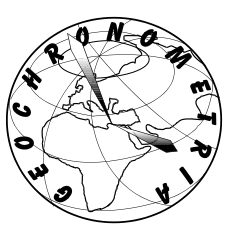

\title{
HISTORICAL MORTARS DATING FROM OSL SIGNALS OF FINE GRAIN FRACTION ENRICHED IN QUARTZ
}

\author{
GIUSEPPE STELLA ${ }^{1,2}$, DOROTEA FONTANA ${ }^{1,3}$, ANNA MARIA GUELI ${ }^{1}$ \\ and SEBASTIANO OLINDO TROJA ${ }^{1}$ \\ ${ }^{I}$ PH3DRA Laboratories (Physics for Dating Diagnostic Dosimetry Research and Applications), Dipartimento di Fisica e Astronomia, \\ Università di Catania \& INFN Sezione di Catania, Via Santa Sofia 64, 95123 Catania, Italy \\ ${ }^{2}$ Earth Sciences Dep., Faculty of Science and Technology, University of Coimbra, \\ IMAR-CMA, Rua Sílvio Lima, 3030-790 Coimbra, Portugal \\ ${ }^{3}$ Laboratorio di Fisica e Tecnologie relative - UniNetLab, Dipartimento di Fisica e Chimica, Università degli Studi di Palermo, \\ Viale delle Scienze, Edificio 18, 90128 Palermo, Italy
}

\begin{abstract}
In the last years the mortar dating through Optically Stimulated Luminescence (OSL) techniques has become a viable support for chronological estimations (date of construction or restoration episodes) of historical buildings. However, the dating of mortar has still open issues mainly regarding the assessment of the bleaching degree of quartz, the analysis of the OSL processes for this type of samples and the need to do appropriate tests for the most correct evaluation of the equivalent dose. This paper discusses the results obtained by OSL dating (blue diode stimulation) on the polymineral fine grain phase, enriched in quartz, extracted from lime mortar samples collected from different sites. Thermal transfer effects, through the behaviour of Equivalent Dose (ED) and recovery tests, degree and time of bleaching were studied. For each mortar sample the adjacent brick was collected; in some cases, sampling of the bricks bracketing a mortar layer was a possibility, thus obtaining a direct comparison with the standard thermoluminescence (TL) dating on the bricks.

The results obtained show, for this set of samples, the possibility of dating the mortars through the use of the fine grain fraction provided of a suitable chemical-physical preparation procedure and the verification of the bleaching conditions.
\end{abstract}

Keywords: historical mortars, luminescence dating, partial bleaching test, preheating test, age model.

\section{INTRODUCTION}

Luminescence measurements of mortars that were initially applied in retrospective dosimetry made use of the OSL emissions of sand-sized quartz $(90-180 \mu \mathrm{m})$, (Bøtter-Jensen et al., 2000b). These confirmed that the grains were bleached to a considerable degree during mixing. The results show the potential of using mortars

Corresponding author: G. Stella

e-mail: giuseppe.stella@ct.infn.it for dosimetric purposes, although they cannot be taken as evidence that, in principle, the mortars are datable. A first attempt to perform optical dating on mortars was carried out by Zacharias et al. (2002) on 90-250 $\mu \mathrm{m}$ quartz inclusions extracted from samples taken from two Byzantine churches. The authors also performed TL dating on brick fragments associated with the mortars. The results were characterized by quite large uncertainties and the lack of material prevented from further research. Goedicke (2003), using a model-calculation on samples of known 
age, suggested the use of OSL-decay curves to evaluate the bleaching of different quartz grain size fractions during manufacture and the possibility of using the conventional SAR protocol for dating.

The difficulty to extract pure coarse grain quartz fractions of sufficient quantity from sand used as inert in mortar, has led other authors (Gueli et al., 2010) to study the luminescent emission from polymineral fine grain phase "enriched in quartz" through HF etching procedures during preparation phase of the samples (Prasad, 2000; Mauz and Lang, 2004). The set of studies so far cited, have confirmed the potential of mortars for dating but have not tackled in detail other issues related to the methodology for the equivalent dose determination and, also, the related experimental steps such as preheating temperature, recovery, recuperation and partial bleaching tests, typically addressed for sediment samples.

Goedicke (2011) has discussed all the problems related to mortar dating including the most suitable methods of equivalent dose and dose rate determination, showing all the adversary properties known from sediments: for instance partial bleaching, low signal and slow decay.

In this paper, in accordance with directions of Goedicke (2011) for mortar dating, OSL measurements by SAR method on polymineral fine grain fraction enriched in quartz are made. The thermal transfer effects were studied through the behaviour of ED and recovery test values against preheating temperature (Choi et al., 2003; Thomas et al., 2003; Kiyak and Canel, 2006). In order to investigate the degree of bleaching, the ED frequency distributions (Olley et al., 1998; Murray and Olley, 2002; Goedicke, 2003; Saini and Mujtaba, 2010) and time of bleaching in the easy-to-bleach OSL traps (Agersnap Larsen et al., 2000) were studied. The OSL ages were obtained using the Central Age Model (CAM) (Galbraith et al., 1999) and the results were compared with TL dating from bricks associated with the mortars.

\section{EXPERIMENTAL DETAILS}

The studied samples were taken from three historical buildings located in different geographical areas. The monastery of Castelletto Cervo (Vercelli, Italy) and the church of Notre Dame de la Place (Bordeaux, France) were dated within a wider project of the GdRE European Group (TCA - Terres Cuites Architecturales et nouvelles methods de datation). The Convento di San Francesco alla Collina (Paternò, Italy) was dated within a large restoration program (Gueli et al., 2010). Table 1 shows, for each structure, the presumed age, the ID and the kind of sample as well as the details of sampling points.

Artificial luminescence signals were induced by the ${ }^{90} \mathrm{Sr}-{ }^{90} \mathrm{Y}$ calibrated beta sources integrated in the Risø systems delivering, respectively, $6 \mathrm{~Gy} / \mathrm{min}$ and $1.32 \mathrm{~Gy} / \mathrm{min}$ for both mortars and bricks. ${ }^{241} \mathrm{Am}$ calibrated alpha source delivering $2.7 \mathrm{~Gy} / \mathrm{min}$ was used to determine the luminescence efficiency coefficient $\mathrm{k}$ neces- sary to correct the alpha dose contribution to the annual dose (Aitken, 1985; Guibert et al., 2009).

TL for bricks and OSL and IRSL (InfraRed Stimulated Luminescence) for mortars, were performed using the semi-automated Risø readers (TL-DA-10 and TL-DA-15) with EMI 9235QA photomultipliers (Bøtter-Jensen, 1997; Bøtter-Jensen et al., 2000a). TL glow curves were recorded in the TL-DA-10 detection system using Corning 7-59 and Schott BG-12 optical filters. OSL and IRSL signals were obtained using TL-DA-15 reader equipped, respectively, with 41 blue LEDs $(470 \pm 30 \mathrm{~nm})$ and with a laser diode $(830 \pm 10 \mathrm{~nm})$. The stimulation units delivered $\sim 30 \mathrm{mWcm}^{-2}$ for OSL and $\sim 240 \mathrm{mWcm}^{-2}$ for IRSL at $90 \%$ power. Both OSL and IRSL emissions were detected using an Hoya U340 optical filter.

\section{SAMPLE PREPARATION}

After removal of two external millimetres, the mortar samples were pre-treated with $10 \% \mathrm{H}_{2} \mathrm{O}_{2}$ for four days, to remove organic material, and with $20 \%$ hydrochloric acid for $120 \mathrm{~min}$ to dissolve carbonates. With the aim of finding the most effective HF treatment to isolate the finegrained enriched in quartz fraction and eliminate feldspar component, different etching treatments were tested (Prasad, 2000; Mauz and Lang, 2004).

The powder obtained was divided in different parts, the first was not treated while the others were treated with $20 \% \mathrm{HF}$ at RT for time between 2 and 20 minutes. Sub-

Table 1. Details for the samples studied in this work with the site of sampling, the ID number, the material and the sampling point.

\begin{tabular}{|c|c|c|c|c|}
\hline \multirow[b]{2}{*}{ Site } & \multirow[b]{2}{*}{ ID Sample } & \multirow[b]{2}{*}{ Sample } & \multicolumn{2}{|c|}{ Sampling point } \\
\hline & & & Wall & $\begin{array}{l}\text { Height }^{*} \\
\text { (cm) }\end{array}$ \\
\hline \multirow{3}{*}{$\begin{array}{l}\text { Castelletto Cervo } \\
\text { (Vercelli, Italy) } \\
\text { (XI - XII centuries) }\end{array}$} & $\begin{array}{l}\text { TLO_M } \\
\text { TLO_B } \\
\end{array}$ & $\begin{array}{l}\text { Mortar } \\
\text { Brick } \\
\end{array}$ & $\begin{array}{l}\text { Western } \\
\text { (inside) }\end{array}$ & 175 \\
\hline & $\begin{array}{l}\text { TL5_M } \\
\text { TL5_B } \\
\end{array}$ & $\begin{array}{l}\text { Mortar } \\
\text { Brick } \\
\end{array}$ & $\begin{array}{l}\text { South } \\
\text { (inside) }\end{array}$ & 150 \\
\hline & $\frac{\frac{\text { TLOSL_B1 }}{\text { TLOSL_M }}}{\text { TLOSL_B2 }}$ & $\begin{array}{l}\text { Brick } \\
\text { Mortar } \\
\text { Brick } \\
\end{array}$ & $\begin{array}{l}\text { Bell tower, } \\
\text { upper level } \\
\text { (inside) }\end{array}$ & 160 \\
\hline \multirow{2}{*}{$\begin{array}{l}\text { San Francesco alla } \\
\text { Collina } \\
\text { (Paternò, Italy) } \\
\text { (X - XII centuries) }\end{array}$} & $\begin{array}{l}\text { MPA7 } \\
\text { BPA7 }\end{array}$ & $\begin{array}{l}\text { Mortar } \\
\text { Brick } \\
\end{array}$ & $\begin{array}{l}\text { South-est } \\
\text { (inside) }\end{array}$ & 155 \\
\hline & $\begin{array}{l}\text { MPA8 } \\
\text { BPA8 } \\
\end{array}$ & $\begin{array}{l}\text { Mortar } \\
\text { Brick } \\
\end{array}$ & $\begin{array}{l}\text { South-est } \\
\text { (inside) }\end{array}$ & 160 \\
\hline \multirow{2}{*}{$\begin{array}{l}\text { Notre Dame de la } \\
\text { Place } \\
\text { (Bordeaux, France) } \\
\text { (V - VII centuries) }\end{array}$} & $\frac{\text { NDLP_B1 }}{\text { NDLP_M }}$ & $\begin{array}{l}\text { Brick } \\
\text { Mortar }\end{array}$ & \multirow{2}{*}{$\begin{array}{l}\text { South } \\
\text { (inside) }\end{array}$} & \multirow{2}{*}{150} \\
\hline & NDLP_B2 & Brick & & \\
\hline
\end{tabular}

*height respect to the planking level 
sequently, they were washed in $10 \% \mathrm{HCl}$ for 25 minutes, to remove fluorides, and then the $4-11 \mu \mathrm{m}$ fraction was selected and deposited onto $9.8 \mathrm{~mm}$ diameter discs.

The purity of fractions was the evaluated by the coefficient $\mathrm{R}$ that is the result of the ratio between postIR-OSL/T2 and OSL/T1 intensities. Where OSL/T1 represents the OSL signal normalized by $\mathrm{T} 1$ test dose and postIR-OSL/T2 the OSL emission obtained after IR stimulation normalized by $\mathrm{T} 2$ test dose.An $\mathrm{R}$ value close to unity indicates that the signal comes from a fraction free of feldspars (Mauz and Lang, 2004; Prasad, 2000; Shen et al., 2007; Zhang and Zhou, 2007). The results obtained (Table 2) show, for all samples, that the most enriched quartz fraction is obtained with an HF etching at 20\% for 15-20 minutes.

For brick samples a procedure to obtain polymineral fine grain phase with PH3DRA standard protocol was used (Guibert et al., 2009). This procedure is divided in the different steps reported therein. The outer layers were removed by two millimetres, then the sample was crushed and sieved and the fraction below $40 \mu \mathrm{m}$ was selected. Next, the following, etching procedures were performed: $10 \% \mathrm{HCl}$ for $1 \mathrm{~h}$ to remove the carbonate, $10 \% \mathrm{H}_{2} \mathrm{O}_{2}$ for 48 hours to remove the organic component, $1 \% \mathrm{HF}$ for 1 hour to remove clay and $10 \% \mathrm{HCl}$ for 25 minutes to eliminate fluorosilicates that had possibly formed. Through a sedimentation procedure, polymineral fine grain fraction in the range of 4-11 $\mu \mathrm{m}$ was obtained and then deposited onto $9.8 \mathrm{~mm}$ diameter discs.

\section{MORTARS DATING: OSL MEASUREMENTS}

\section{Preheating test}

In dating of young samples as mortars, the OSL signal is normally measured following a relatively low $\left(\leq 220^{\circ} \mathrm{C}\right)$ preheating treatment in order to limit the heating transfer of charge from deep energy levels to the OSL traps which influences the dating significantly. The thermal transfer can in fact cause overestimation of the equivalent dose and, therefore, an overestimation of age (Bailiff and Holland, 2000; Murray and Clemmensen, 2001; Ramzaev et al., 2008; Rhodes, 2000; Wallinga et al., 2001).

In this work, for five aliquots of each sample ED measurements as a function of preheating temperature $\left(160-260^{\circ} \mathrm{C}\right)$ were made (Choi et al., 2003; Thomas et al., 2003; Kiyak and Canel, 2006). Each value of dose was determined using the modified SAR protocol (Murray and Wintle, 2003). The cycle of SAR protocol was repeated 7 times using increasing regeneration doses from 1.5 to $15 \mathrm{~Gy}$. The integral signal of the first $2 \mathrm{~s}$ was used as OSL intensity, after subtraction of the background calculated from the last $3.5 \mathrm{~s}$ of the total stimulation time. The uncertainties were quantified on the basis of statistical counting of luminescence signals and applying error propagation.

Following the test dose, a cut heat of $160^{\circ} \mathrm{C}$ was applied. For minimizing the effects of charge remained in the light insensitive trap, at the end of each SAR cycle, an OSL measurement at $280^{\circ} \mathrm{C}$ for $40 \mathrm{~s}$ was carried out. On the same aliquots a recovery test in a preheating temperature range between $160^{\circ} \mathrm{C}$ and $240^{\circ} \mathrm{C}$ was done (Choi et al., 2003; Kiyak and Canel, 2006). In such a test, a SAR measurement is applied to an aliquot which has been irradiated with a laboratory dose after its optical bleaching. In the absence of thermal transfer, it is expected that the ratio ( $\mathrm{R}=$ measured / given dose) is close to unity; in the presence of thermal transfer, it takes values greater than 1 . The recovery test values are considered acceptable

Table 2. Mortar ID sample, \% concentration of HF, time of etching and values of ratio (R) against time $20 \%$ HF etching determined for each sample.

\begin{tabular}{|c|c|c|c|c|c|c|c|}
\hline ID sample & Etching & $\begin{array}{l}\text { Etching time } \\
\text { (min) }\end{array}$ & $R$ & ID sample & Etching & $\begin{array}{c}\text { Etching time } \\
\text { (min) }\end{array}$ & $R$ \\
\hline \multirow{6}{*}{ TLO_M } & No HF & 0 & $0.45 \pm 0.03$ & \multirow{6}{*}{ MPA7 } & No HF & 0 & $0.48 \pm 0.03$ \\
\hline & \multirow{5}{*}{$20 \% \mathrm{HF}$} & 2 & $0.56 \pm 0.03$ & & \multirow{5}{*}{$20 \% \mathrm{HF}$} & 2 & $0.64 \pm 0.04$ \\
\hline & & 5 & $0.78 \pm 0.05$ & & & 5 & $0.75 \pm 0.05$ \\
\hline & & 10 & $0.88 \pm 0.05$ & & & 10 & $0.87 \pm 0.04$ \\
\hline & & 15 & $0.99 \pm 0.03$ & & & 15 & $1.01 \pm 0.03$ \\
\hline & & 20 & $0.98 \pm 0.04$ & & & 20 & $0.98 \pm 0.04$ \\
\hline \multirow{6}{*}{ TL5_M } & No HF & 0 & $0.42 \pm 0.04$ & \multirow{6}{*}{ MPA8 } & No HF & 0 & $0.40 \pm 0.03$ \\
\hline & & 2 & $0.58 \pm 0.03$ & & \multirow{5}{*}{$20 \% \mathrm{HF}$} & 2 & $0.51 \pm 0.04$ \\
\hline & & 5 & $0.72 \pm 0.04$ & & & 5 & $0.79 \pm 0.04$ \\
\hline & $20 \% \mathrm{HF}$ & 10 & $0.95 \pm 0.03$ & & & 10 & $0.92 \pm 0.04$ \\
\hline & & 15 & $1.00 \pm 0.04$ & & & 15 & $0.99 \pm 0.03$ \\
\hline & & 20 & $0.96 \pm 0.05$ & & & 20 & $1.02 \pm 0.04$ \\
\hline \multirow{6}{*}{ TLOSL_M } & No HF & 0 & $0.39 \pm 0.03$ & \multirow{6}{*}{ NDLP_M } & No HF & 0 & $0.56 \pm 0.03$ \\
\hline & \multirow{5}{*}{$20 \% \mathrm{HF}$} & 2 & $0.50 \pm 0.03$ & & \multirow{5}{*}{$20 \% \mathrm{HF}$} & 2 & $0.68 \pm 0.04$ \\
\hline & & 5 & $0,62 \pm 0.03$ & & & 5 & $0.87 \pm 0.03$ \\
\hline & & 10 & $0.88 \pm 0.04$ & & & 10 & $0.95 \pm 0.05$ \\
\hline & & 15 & $0.98 \pm 0.03$ & & & 15 & $1.03 \pm 0.06$ \\
\hline & & 20 & $0.99 \pm 0.03$ & & & 20 & $1.02 \pm 0.04$ \\
\hline
\end{tabular}


in the range between 0.90 and 1.10 (Murray and Wintle, 2003). The behaviour of ED and R (measured/given dose) values vs. preheating temperatures, obtained for each sample, are shown in Fig. 1(a-c) and 1(d-f), respectively. The samples are grouped by site of collection.

For the samples TL0_M (Fig. 1a) and NDLP_M (Fig. 1c) the ED values are independent of preheating temperature in the range of $200-240^{\circ} \mathrm{C}$ while at higher temperatures the ED significantly increases. This can be attributed to thermal transfer effects. Therefore the preheat temperature chosen and used for ED determination was of $220^{\circ} \mathrm{C}$ for $10 \mathrm{~s}$.

All the other samples show ED plateau values in the range $180-220^{\circ} \mathrm{C}$ (Fig. 1a and Fig. 1b). Therefore the preheating temperature value used for ED determination was of $200^{\circ} \mathrm{C}$ for $10 \mathrm{~s}$. The results of recovery test (Fig. $\mathbf{1}(\mathbf{d}-\mathbf{f})$ ) confirm that the rising trend in the preheat-plateau could be the result of thermal transfer during preheating of the samples prior to OSL measurements.

\section{ED determination and partial bleaching test}

For ED determination of each sample, the modified SAR protocol (Murray and Wintle, 2003), the preheating values obtained from previous tests and a cut heat of $160^{\circ} \mathrm{C}$ were used. The degree of bleaching is evaluable from histograms as shown in Fig. 2 for each measured sample (Olley et al., 1998; Murray and Olley, 2002; Goedicke, 2003; Saini and Mujtaba, 2010). The individual ED values were entered into bins of $0.1 \mathrm{~Gy}$ and so the frequency distributions were obtained.

The frequency distributions and related Gaussian fits (with standard deviations) show a well-bleached degree for each sample. However, these diagrams do not take into account the equivalent dose uncertainties; the maximum of the histogram may therefore not correspond with the "true" natural dose, unless the errors are more or less uniform (Goedicke, 2003). So, for age calculation, we used the radial plot technique that is discussed in the next section.

A further test to evaluate the bleaching time was performed for each sample. According to the paper of Agersnap Larsen et al. (2000), the effect of partial bleaching of the OSL signal was studied by exposing an irradiated aliquot to light using different illumination time, prior to the OSL measurements, using the measuring sequence detailed in Table 3.

The test consists of a laboratory irradiation and an optical resetting event using various illumination times $\Delta t$ from $0 \mathrm{~s}$ to $100 \mathrm{~s}$. The intent of the pre-heat phase $\left(200^{\circ} \mathrm{C}\right.$ for $10 \mathrm{~s}$ ) is to empty the shallow traps in order to reproduce as closely as possible the natural situation. A blue diode stimulation at $160^{\circ} \mathrm{C}$ prevents the thermal charge release from these traps during the Continuous Wave OSL (CW-OSL) readout (Agersnap Larsen et al., 2000).

Fig. 3a shows, as an example for the MPA8 mortar sample, that a time of $10 \mathrm{~s}$ is sufficient to bleach OSL emissions. The ratio between the partially bleached and the unbleached CW-OSL curves (Fig. 3b) describes the bleaching effects and gives direct information of the depletion degree for each illumination time. It is therefore expected that the grains will be well bleached and negligible charge should be remaining in the easy-to-bleach OSL traps at the time of laying with a similar solar exposition time.

\section{Radial plot analysis}

To determine the well-bleached population and the best representation of the true age from this distribution, the Central Age Model (CAM) of Galbraith et al. (1999) was explored (Fig. 4). In this model, the single true $\log (E D)$ are not equal, but are a random sample from a normal distribution with mean $E D$ and standard deviation $\sigma$. It is graphically represented through the radial plot method, where, the position on the $\mathrm{x}$-axis is a measure of the precision ( $\mathrm{t} / \mathrm{se})$ with which ED is known. This axis is also expressed in terms of the relative error (se/t expressed as a percentage). Radial plots were obtained using the RadialPlotter software that can be downloaded free of charge from http://pvermees.andropov.org/radialplotter (Vermeesch, 2009).

Table 4 reports, for each mortar samples, the number of aliquots, the equivalent un-weighted mean doses with standard deviations obtained by Gaussian fit and as the Central value of Radial Plots .

\section{BRICK DATING: THERMOLUMINESCENCE MEASUREMENTS}

The ED values for bricks were determined using TL measurements and especially the additive dose method on the polymineral fine grain phase. For each sample, 24 aliquots were prepared and grouped into six. The first group was used for measuring the natural TL signal. The remaining groups were irradiated serially and incrementally using a calibrated beta source. TL glow curves were recorded by heating the aliquots up to $500^{\circ} \mathrm{C}$ at a constant

Table 3. Procedure for partial bleaching test are resumed: annealing, irradiation and preheating cycle to obtain the laboratory dose; blue diode stimulation for partial bleaching; preheating and OSL readout to obtain final curves.

\begin{tabular}{|c|c|c|c|}
\hline Step & Treatment & & \\
\hline 1 & $\mathrm{TL} @ 500^{\circ} \mathrm{C}, 100 \mathrm{~s}$ & Annealing & \multirow{3}{*}{ Laboratory dose } \\
\hline 2 & Irradiation $\beta$ & Irradiation & \\
\hline 3 & $\mathrm{Ph} @ 200{ }^{\circ} \mathrm{C}, 10 \mathrm{~s}$ & Preheat & \\
\hline 4 & $\begin{array}{l}\text { Blue-diode@160 } 160^{\circ} \mathrm{C} \\
\Delta \mathrm{t}=(0 ; 0.2 ; 1 ; 10 ; 100) \mathrm{s}\end{array}$ & Bleaching & Partial bleaching \\
\hline 5 & $\mathrm{Ph} @ 200^{\circ} \mathrm{C}, 10 \mathrm{~s}$ & Preheating & \multirow{2}{*}{ OSL Curve } \\
\hline 6 & OSL@125ㄷ, $40 \mathrm{~s}$ & OSL readout & \\
\hline
\end{tabular}



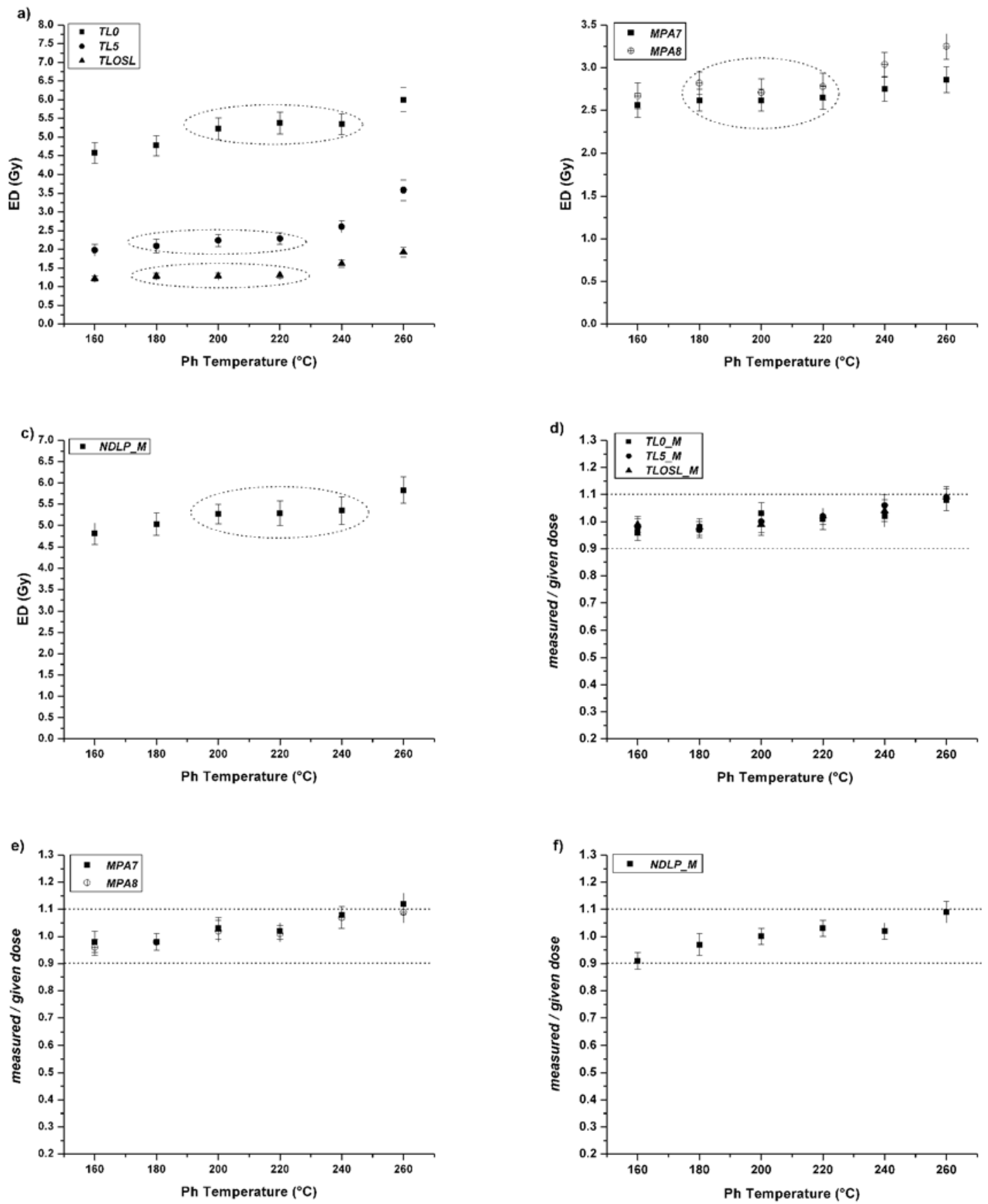

Fig. 1. $E D(a, b, c)$ and recovery test values $(d, e, f)$ against preheating temperature for mortar samples. 
a)

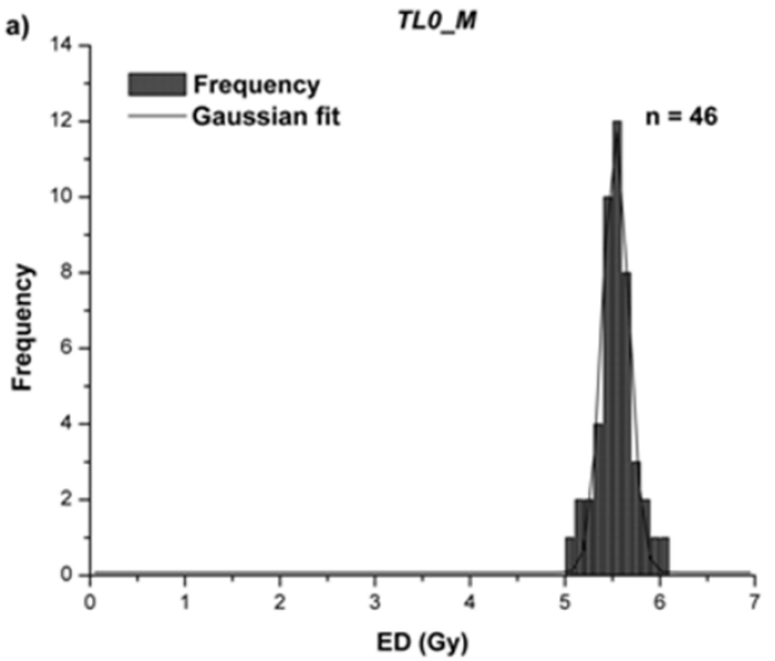

c)

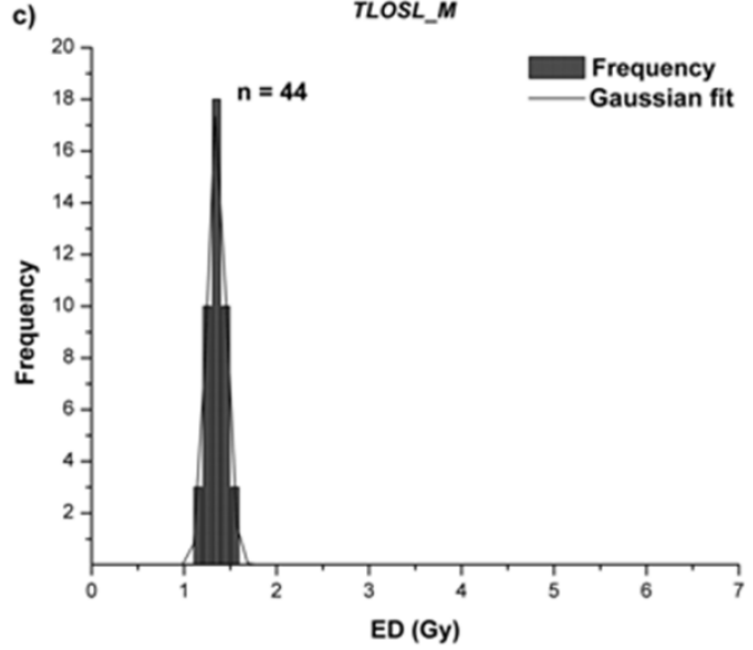

e)

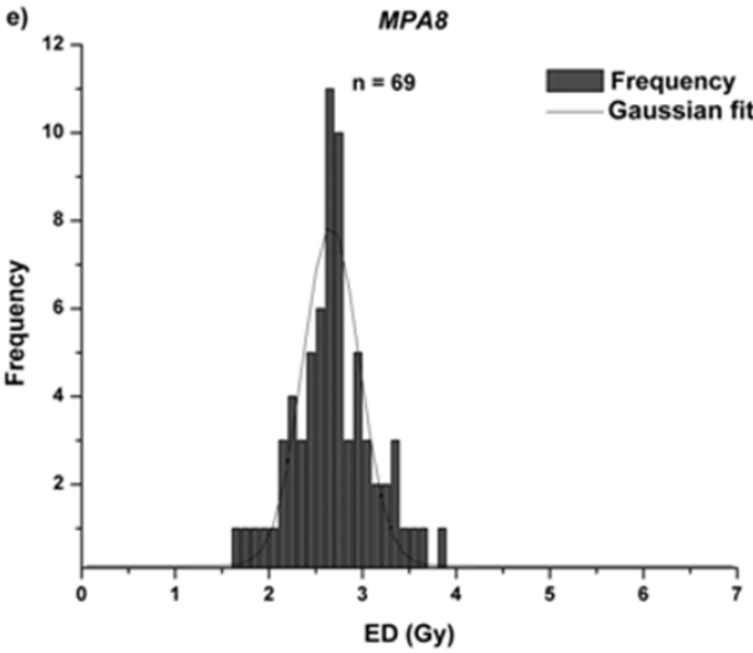

b)

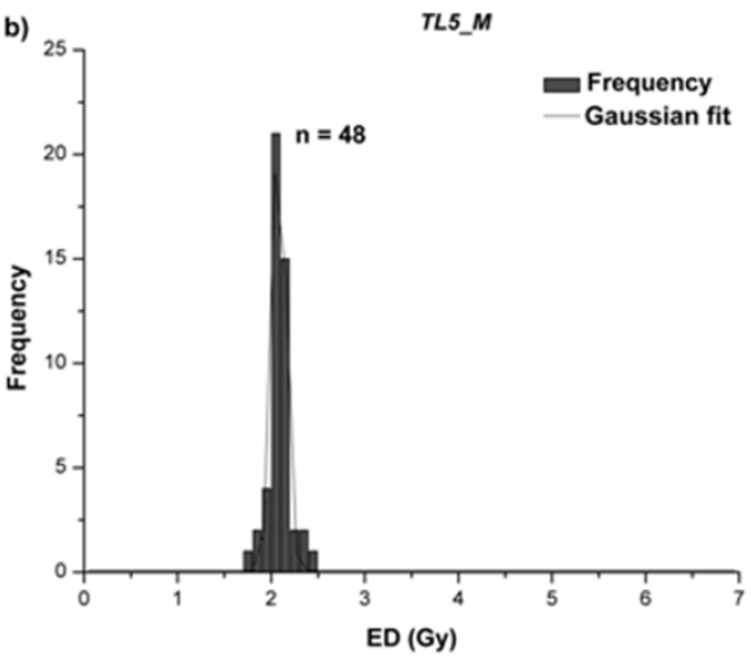

d)
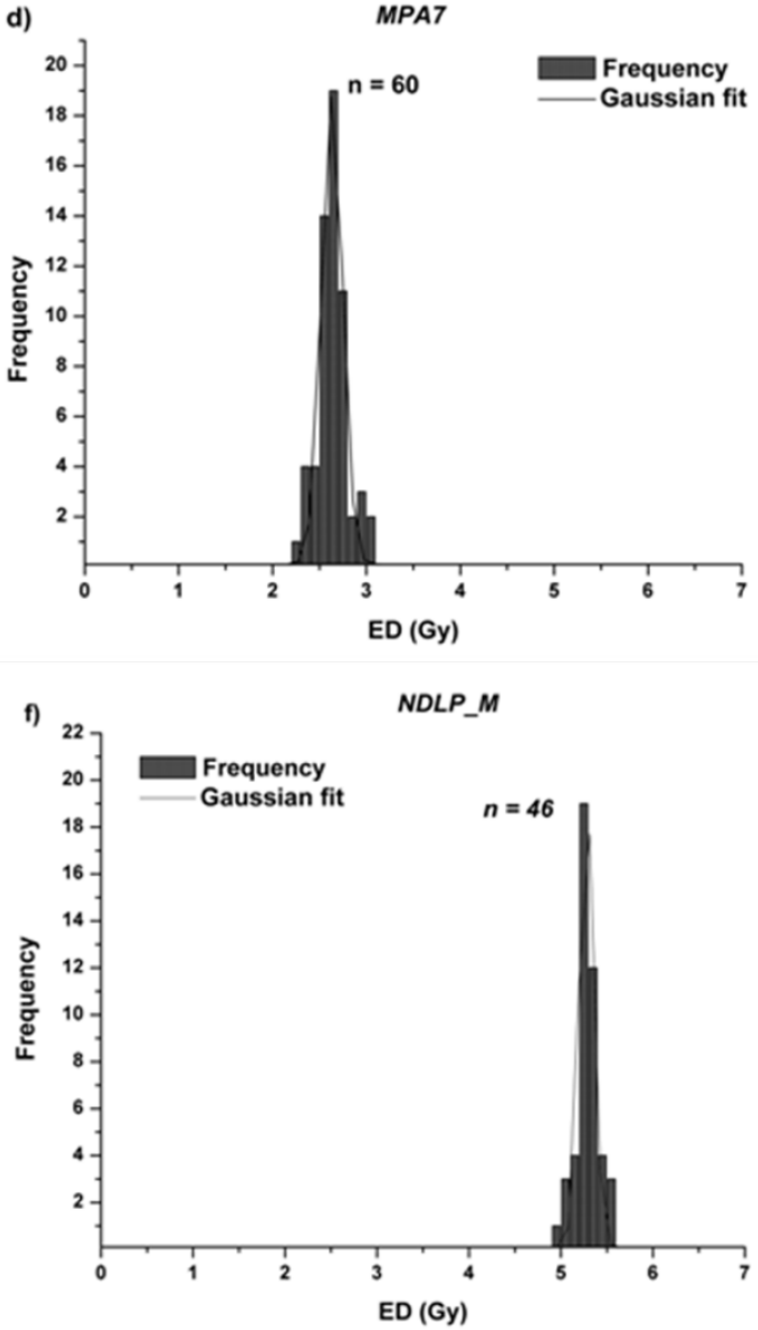

Fig. 2. ED frequency distributions and Gaussian fit for mortar samples. 

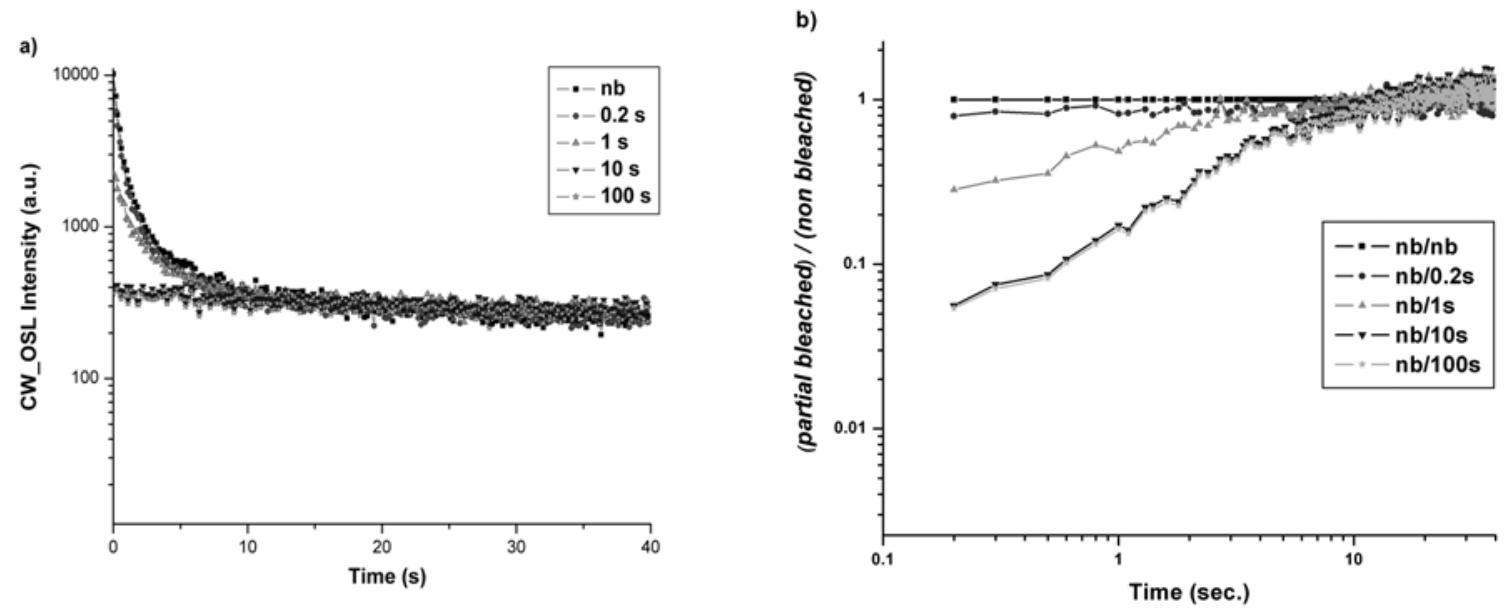

Fig. 3. a) OSL curve for not bleached (nb) MPA8 sample and after 0.2, 1, 10 and 100 seconds of bleaching time with blue-diode@160 $\mathrm{C}$; b) Ratio between the partially bleached and non-bleached (nb) CW-OSL curves.

heating rate of $5^{\circ} \mathrm{C} / \mathrm{s}$ in an ultrapure nitrogen atmosphere. The inter-aliquot intensity variations were corrected by second glow-curve normalisation. The temperature region between 300 and $350^{\circ} \mathrm{C}$ TL $\left(280-390^{\circ} \mathrm{C}\right.$ plateau) was used for $\mathrm{ED}$ calculation $\left(\mathrm{Q}_{\beta}\right)$. The same aliquots were then exposed to small and incrementing beta doses and a growth curve was constructed. The intercept of the curve on the dose axis is the correction value for supralinear growth (q $)$ (Aitken, 1985). All samples showed a growth linear luminescent behaviour $v s$. dose. Just as an example, Fig. 5 shows the straight growth lines of TLOSL B2 sample from which the values of $\mathrm{Q}_{\beta}(\mathrm{a})$ and the correction $\mathrm{q} \beta$ (b) were obtained.

For each sample measurements of natural loss of luminescence over time were performed (Aitken, 1985). The results obtained exclude the presence of anomalous fading.

\section{DOSE RATE DETERMINATION}

Annual dose components due to radioelements in the bricks and in the mortars samples were calculated using concentration values of $\mathrm{U}, \mathrm{Th}, \mathrm{Rb}$ and $\mathrm{K}$ (Table 5) determined by the ICP-MS technique using the conversion factors of Guérin et al. (2011).

The alpha contribution to the annual dose thus calculated were compared with integral thick source alphacounting measurements (unit AL 03 system) (Table 6) in order to obtain indications about the radioactive equilibrium of the Uranium chain. The alpha counting in the pair coincidences counting mode can in fact be used to estimate Th contents and the alpha dose (Feathers et al., 2008).
Table 4. Number of aliquots, ED un-weighted mean by Gaussian fit, Central Value by Radial Plot and relative standard deviations obtained for mortar samples.

\begin{tabular}{lccccc}
\hline Sample & $\begin{array}{c}\text { Number of } \\
\text { aliquots } \\
(\boldsymbol{n})\end{array}$ & $\begin{array}{c}\text { Mean ED } \\
(\mathbf{G y})\end{array}$ & SD & $\begin{array}{c}\text { Central } \\
\text { Value } \\
(\mathbf{G y})\end{array}$ & SD \\
\hline TL0_M & 46 & 5.53 & 0.20 & 5.53 & 0.06 \\
\hline TL5_M & 48 & 2.08 & 0.12 & 2.08 & 0.03 \\
\hline TLOSL_M & 44 & 1.35 & 0.10 & 1.34 & 0.03 \\
\hline MPA7 & 60 & 2.64 & 0.16 & 2.63 & 0.04 \\
\hline MPA8 & 69 & 2.69 & 0.43 & 2.66 & 0.10 \\
\hline NDLP_M & 46 & 5.28 & 0.12 & 5.26 & 0.05 \\
\hline
\end{tabular}

Table 5. ID and type of samples, $U, T h, R b$ and $K$ contents by ICP-MS technique.

\begin{tabular}{llrrrr}
\hline ID & Sample & $\mathbf{U}(\mathbf{p p m})$ & \multicolumn{1}{c}{ Th $(\mathbf{p p m})$} & $\mathbf{R b}(\mathbf{p p m})$ & $\mathbf{K}(\%)$ \\
\hline TL0_M & Mortar & $4.40 \pm 0.21$ & $13.30 \pm 0.85$ & $30 \pm 1$ & $4.08 \pm 0.01$ \\
\hline TL0_B & Brick & $5.30 \pm 0.25$ & $17.00 \pm 1.09$ & $105 \pm 5$ & $1.50 \pm 0.01$ \\
\hline TL5_M & Mortar & $2.76 \pm 0.13$ & $3.77 \pm 0.24$ & $43 \pm 2$ & $1.09 \pm 0.01$ \\
\hline TL5_B & Brick & $4.99 \pm 0.24$ & $15.20 \pm 0.97$ & $102 \pm 4$ & $1.64 \pm 0.01$ \\
\hline TLOSL_B1 & Brick & $5.26 \pm 0.25$ & $17.00 \pm 1.09$ & $105 \pm 5$ & $1.50 \pm 0.01$ \\
\hline TLOSL_M & Mortar & $1.85 \pm 0.09$ & $1.72 \pm 0.11$ & $30 \pm 1$ & $0.64 \pm 0.01$ \\
\hline TLOSL_B2 & Brick & $5.91 \pm 0.28$ & $17.70 \pm 1.13$ & $102 \pm 4$ & $1.63 \pm 0.01$ \\
\hline MPA7 & Mortar & $3.70 \pm 0.06$ & $1.80 \pm 0.03$ & $34 \pm 1$ & $0.72 \pm 0.01$ \\
\hline BPA7 & Brick & $2.60 \pm 0.04$ & $9.40 \pm 0.15$ & $79 \pm 1$ & $2.66 \pm 0.01$ \\
\hline MPA8 & Mortar & $4.44 \pm 0.07$ & $2.97 \pm 0.05$ & $18 \pm 1$ & $0.61 \pm 0.01$ \\
\hline BPA8 & Brick & $3.30 \pm 0.05$ & $10.80 \pm 0.17$ & $85 \pm 1$ & $2.93 \pm 0.01$ \\
\hline NDLP_B1 & Brick & $2.60 \pm 0.04$ & $10.40 \pm 0.28$ & $130 \pm 2$ & $1.54 \pm 0.02$ \\
\hline NDLP_M & Mortar & $5.70 \pm 0.09$ & $4.80 \pm 0.13$ & $57 \pm 1$ & $1.47 \pm 0.01$ \\
\hline NDLP_B2 & Brick & $2.60 \pm 0.04$ & $9.96 \pm 0.26$ & $129 \pm 2$ & $1.52 \pm 0.02$ \\
\hline
\end{tabular}


a) TLO_M

Central value $=5.529+/-0.061$ (2se)

Dispersion $=1.8 \%$
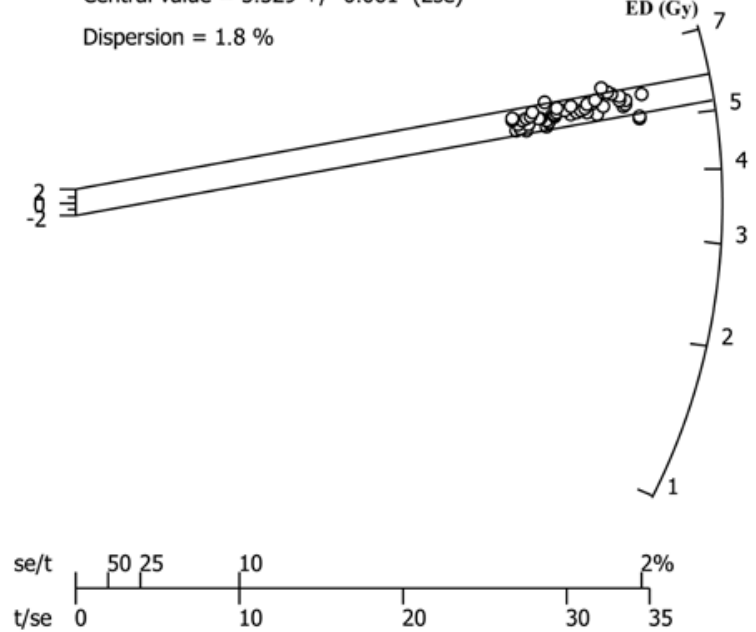

c) TLOSL_M

Central value $=1.342+/-0.029$ (2se)

Dispersion $=6.3 \%$
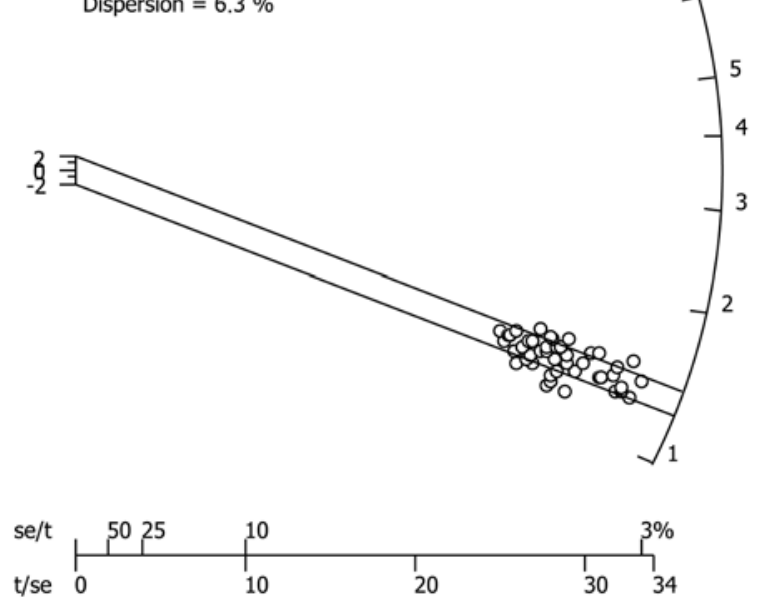

e) MPA8

Central value $=2.66+/-0.1$ (2se)

Dispersion $=16 \%$

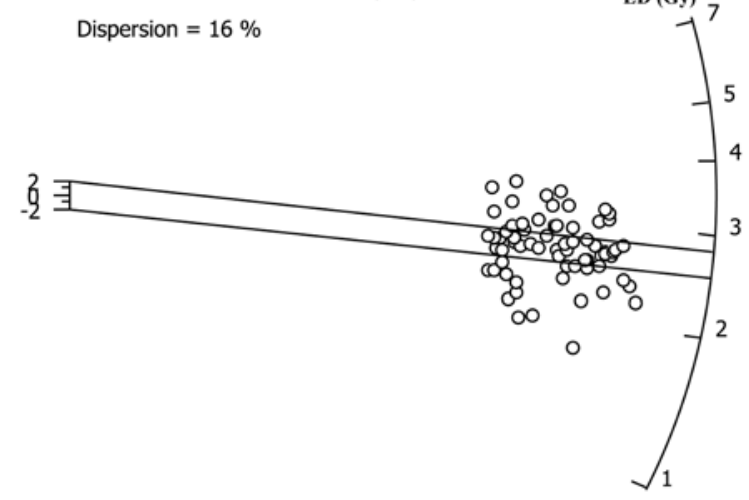

b) TL5_M

Central value $=2.079+/-0.033(2 \mathrm{se})$

Dispersion $=4.2 \%$
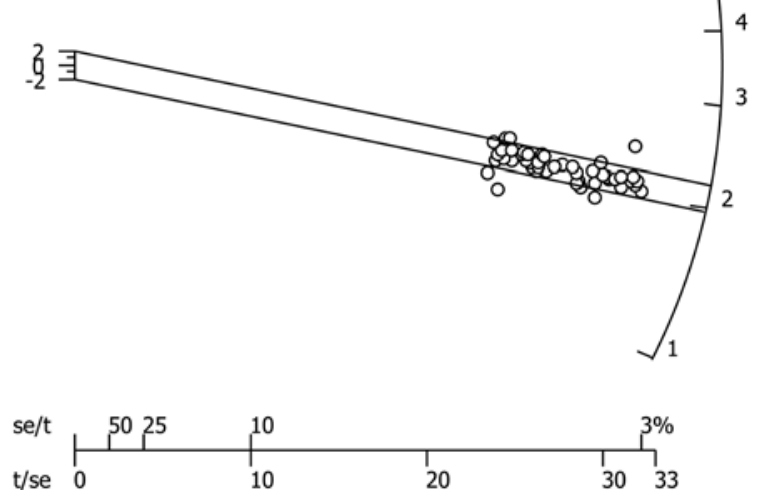

d) MPA7

Central value $=2.626+/-0.043$ (2se)

Dispersion $=5.1 \%$
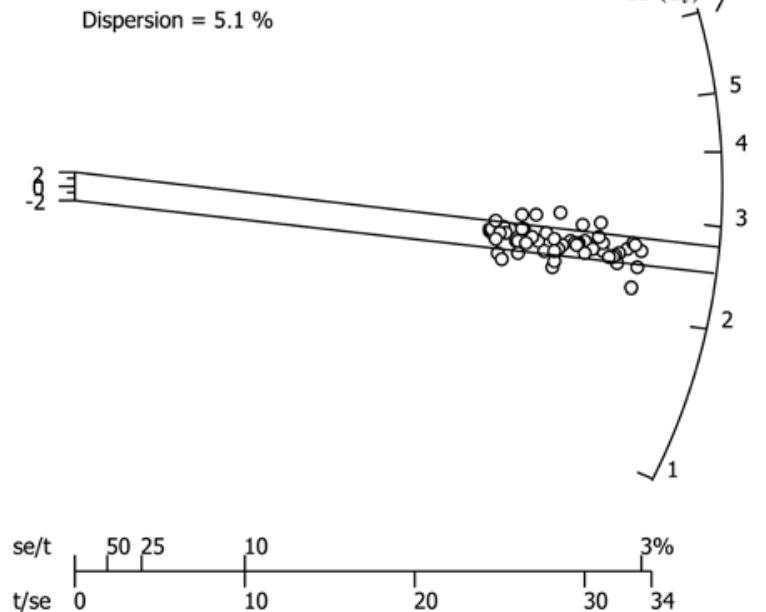

f) NDLP_M

Central value $=5.261+/-0.053$ (2se)

Dispersion $=0 \%$
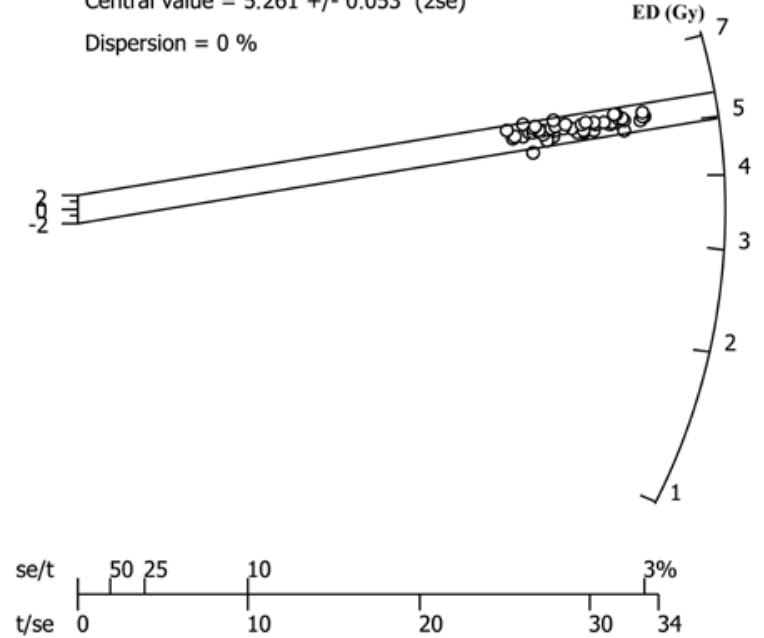

Fig. 4. ED distribution obtained with Radial plots (CAM) for mortar samples. 

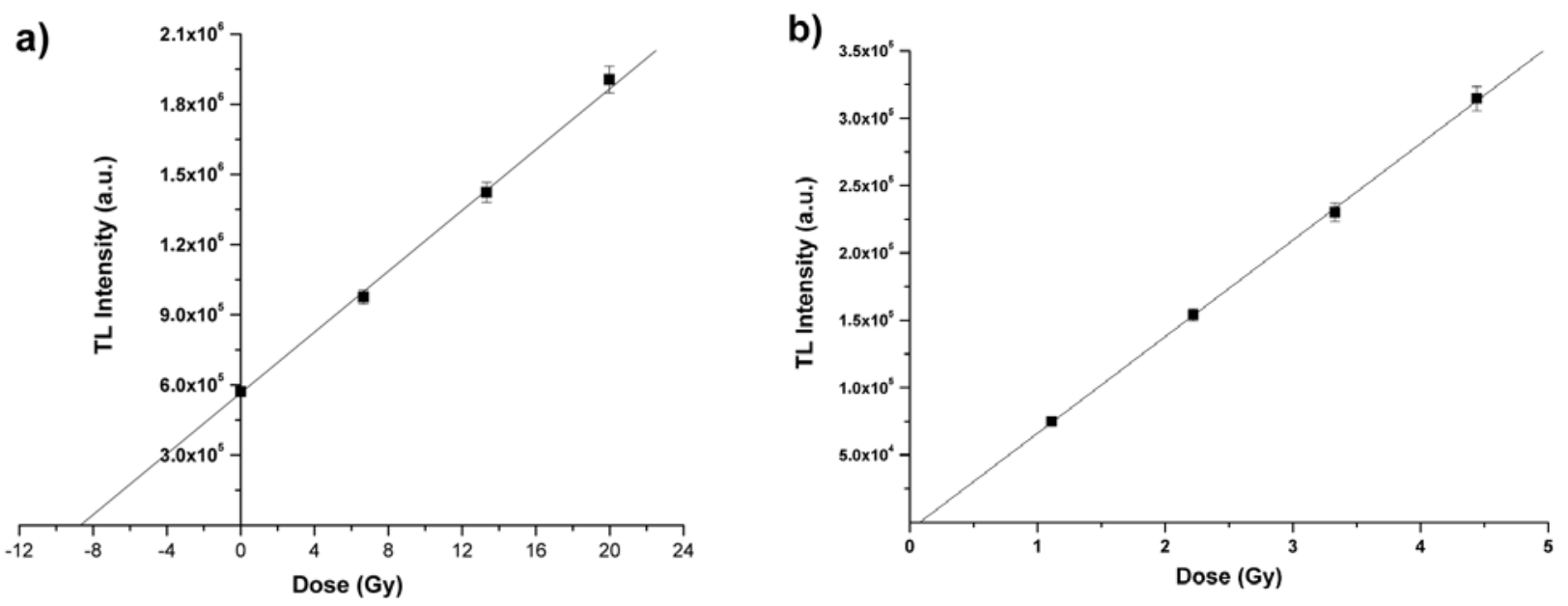

Fig. 5. Growth curves for $Q_{\beta}(a)$ and $q_{\beta}$ (b) calculation for TLOSL_B2 sample.

Table 6. Internal Alpha dose rate: comparison between ones calculated by ICP-MS and ones by alpha counting measurements. Percentage difference between the values obtained with the two techniques ( $\Delta \%)$.

\begin{tabular}{llccc}
\hline & & \multicolumn{3}{c}{ Alpha dose rate (mGy/a) } \\
\cline { 3 - 5 } ID & Sample & $\begin{array}{c}\text { From ICPMass } \\
\text { content }\end{array}$ & Alpha counting & $\Delta \%$ \\
\hline TL0_M & Mortar & $22.11 \pm 0.86$ & $21.58 \pm 0.91$ & 2.40 \\
\hline TL0_B & Brick & $27.35 \pm 1.07$ & $26.86 \pm 0.17$ & 1.79 \\
\hline TL5_M & Mortar & $10.49 \pm 0.41$ & $10.60 \pm 0.44$ & 1.05 \\
\hline TL5_B & Brick & $25.16 \pm 0.97$ & $24.87 \pm 1.00$ & 1.15 \\
\hline TLOSL_B1 & Brick & $27.24 \pm 1.06$ & $26.83 \pm 1.09$ & 1.51 \\
\hline TLOSL_M & Mortar & $6.44 \pm 0.26$ & $6.51 \pm 0.27$ & 1.09 \\
\hline TLOSL_B2 & Brick & $29.57 \pm 1.14$ & $29.85 \pm 1.32$ & 0.95 \\
\hline MPA7 & Mortar & $11.67 \pm 0.16$ & $11.90 \pm 0.52$ & 1.97 \\
\hline BPA7 & Brick & $14.20 \pm 0.16$ & $13.96 \pm 0.61$ & 1.69 \\
\hline MPA8 & Mortar & $14.60 \pm 0.20$ & $14.76 \pm 0.66$ & 1.10 \\
\hline BPA8 & Brick & $17.19 \pm 0.19$ & $16.95 \pm 0.69$ & 1.40 \\
\hline NDLP_B1 & Brick & $14.94 \pm 0.23$ & $14.81 \pm 0.65$ & 0.87 \\
\hline NDLP_M & Mortar & $19.47 \pm 0.27$ & $19.02 \pm 0.79$ & 2.31 \\
\hline NDLP_B2 & Brick & $14.61 \pm 0.22$ & $14.91 \pm 0.70$ & 2.05 \\
\hline
\end{tabular}

Once confirmed the $U$ chain radioactive equilibrium, the alpha dose rate values obtained from $U$ and Th contents (ICP-MS) were used and the internal beta dose from $\mathrm{U}, \mathrm{Th}, \mathrm{K}$ and $\mathrm{Rb}$ was determined.

The dose contributions were corrected on the basis of the experimentally measured porosity factor (W) (Table 7) (Aitken, 1985) and saturation factor (F) estimated on the basis of sampling point (height, inside or outside, etc. ...) and humidity measurements of the samples to the excavation. In this particular case an $\mathrm{F}$ value of $0.3 \pm 0.2$ for all sites was used, except for the samples collected from Notre Dame de La Place for which the value of $0.5 \pm 0.2$ was considered.
The annual environmental dose rate was measured using TL dosimeters (GR200A) enclosed in capsules placed in situ at the sampling points (Gueli et al., 2009). Around each sampling point in situ $\gamma$ dose measurements (Canberra InSpector 1000 spectrometer) were made. The dose values obtained, all within a discrepancy of $3 \%$ compared to the measured value in the sampling point, show a homogeneous gamma dose distribution in the environment constituted by regular sequences of bricks and mortars. Cosmic radiation contribution is calculated according to global considerations by Prescott and Hutton (1988).

Table 7 shows the internal dose rates (Daint and $D_{\beta}$ int), for each sample, corrected for water content together with the annual environmental (gamma + cosmic) dose (Denv).

\section{DISCUSSION}

The tests made for mortars (ED and recovery test values against preheating temperature) show thermal transfer effects for preheating temperature above $220-240^{\circ} \mathrm{C}$. As previously mentioned, these tests were essential to choose the true preheating temperature to avoid overestimation of the equivalent dose. Furthermore, the recovery test values close to 1 , for the preheating temperature used for ED determination, validate the choice of the other experimental parameters, such as test dose and cut heat temperature.

The histograms of ED frequency distribution and the radial plot show a Gaussian behaviour of the dose values indicating that the samples are well-bleached. This is confirmed by partial bleaching test, in fact, the grains turned out well-bleached for stimulation time shorter than 10 seconds, a time comparable to sun exposure during the mixing and layer of the mortar on the structure.

For the evaluation of the annual dose was necessary to determine the alpha dose contribution starting from the contents of ICP-MS with conversion factors in dose and 
Table 7. ID and type of samples, $k$ value, internal dose rate corrected with humidity and porosity factors (W, F) and environmental dose rates.

\begin{tabular}{|c|c|c|c|c|c|c|c|}
\hline ID & Sample & k & W & $\begin{array}{c}\text { Daint_corrected }_{\text {ingla) }} \\
\text { (mGy/a }\end{array}$ & $\begin{array}{c}D_{\text {Bint_corrected }} \\
\text { (mGy/a) }\end{array}$ & $\begin{array}{c}D_{\text {env }} \\
\text { (mGy/a) }\end{array}$ & $\begin{array}{c}\text { Dose rate } \\
\text { (mGy/a) }\end{array}$ \\
\hline TLO_M & Mortar & $0.06 \pm 0.01$ & $0.20 \pm 0.01$ & $20.34 \pm 3.09$ & $3.99 \pm 0.48$ & \multirow{2}{*}{$1.67 \pm 0.05$} & $6.96 \pm 0.56$ \\
\hline TLO_B & Brick & $0.23 \pm 0.01$ & $0.12 \pm 0.01$ & $25.92 \pm 1.59$ & $2.37 \pm 0.10$ & & $10.01 \pm 0.46$ \\
\hline TL5_M & Mortar & $0.07 \pm 0.01$ & $0.30 \pm 0.01$ & $9.26 \pm 1.46$ & $1.12 \pm 0.14$ & \multirow{2}{*}{$1.73 \pm 0.05$} & $3.45 \pm 0.20$ \\
\hline TL5_B & Brick & $0.13 \pm 0.01$ & $0.13 \pm 0.01$ & $23.76 \pm 1.46$ & $2.38 \pm 0.10$ & & $7.13 \pm 0.32$ \\
\hline TLOSL_B1 & Brick & $0.23 \pm 0.02$ & $0.12 \pm 0.01$ & $25.82 \pm 1.59$ & $2.37 \pm 0.10$ & \multirow{3}{*}{$1.47 \pm 0.05$} & $9.83 \pm 0.60$ \\
\hline TLOSL_M & Mortar & $0.06 \pm 0.01$ & $0.21 \pm 0.01$ & $5.92 \pm 0.90$ & $0.78 \pm 0.09$ & & $2.67 \pm 0.13$ \\
\hline TLOSL_B2 & Brick & $0.19 \pm 0.01$ & $0.13 \pm 0.01$ & $27.96 \pm 1.72$ & $2.57 \pm 0.11$ & & $9.38 \pm 0.49$ \\
\hline MPA7 & Mortar & $0.07 \pm 0.01$ & $0.19 \pm 0.01$ & $10.92 \pm 1.58$ & $1.11 \pm 0.13$ & \multirow{2}{*}{$0.68 \pm 0.02$} & $2.58 \pm 0.21$ \\
\hline BPA7 & Brick & $0.10 \pm 0.01$ & $0.15 \pm 0.01$ & $13.06 \pm 0.66$ & $2.61 \pm 0.11$ & & $4.59 \pm 0.18$ \\
\hline MPA8 & Mortar & $0.06 \pm 0.01$ & $0.12 \pm 0.01$ & $13.93 \pm 1.98$ & $1.17 \pm 0.14$ & \multirow{2}{*}{$0.70 \pm 0.02$} & $2.64 \pm 0.18$ \\
\hline BPA8 & Brick & $0.09 \pm 0.01$ & $0.11 \pm 0.01$ & $16.35 \pm 0.79$ & $3.02 \pm 0.12$ & & $5.19 \pm 0.22$ \\
\hline NDLP_B1 & Brick & $0.30 \pm 0.01$ & $0.26 \pm 0.01$ & $12.47 \pm 1.14$ & $1.67 \pm 0.12$ & \multirow{3}{*}{$0.91 \pm 0.04$} & $6.32 \pm 0.39$ \\
\hline NDLP_M & Mortar & $0.05 \pm 0.01$ & $0.07 \pm 0.01$ & $18.54 \pm 4.39$ & $2.07 \pm 0.40$ & & $3.91 \pm 0.50$ \\
\hline NDLP_B2 & Brick & $0.17 \pm 0.01$ & $0.12 \pm 0.01$ & $13.40 \pm 1.12$ & $1.78 \pm 0.12$ & & $4.97 \pm 0.27$ \\
\hline
\end{tabular}

alpha counting measurements. The comparison between the results obtained, all within a discrepancy of $\sim 2 \%$, confirms the absence of problems related to radioactive disequilibrium. With regard to the environmental contribution to the annual dose, mappings with in situ $\gamma$ counter show a uniform degree of dose certainly due to the regular brick-mortar construction.

The dose values thus obtained, for mortar and bricks, were corrected with the factors related to the porosity (W) and the saturation (F). The porosity was experimentally obtained whereas the saturation was estimated. This last evaluation, in agreement with the other groups involved in the dating project considers both the geographical position of the structures and the height of sampling points.
Table 8 shows, for each sample, the technique and the method used for ED determination, the number of aliquots and the ages obtained.

The ages obtained for each mortar sample are in good agreement with the associated brick and with the chronological results obtained for the studied structures, except in the case of the set of samples TLOSL\# taken from the monastery of Castelletto Cervo. In this case, the mortar results to be younger than bricks (coeval between their), and this suggests that it has been inserted in the structure during a restoration phase. This is confirmed both by the elemental composition of bricks similar to that of the other coeval bricks and by the different composition of the mortar samples than the other taken in the structure (TLO_M

Table 8. Details and age results for each sample.

\begin{tabular}{|c|c|c|c|c|c|c|}
\hline Site & ID & Sample & Technique & Method & $\mathrm{n}$ & “Age 2se (a) \\
\hline \multirow{7}{*}{ Castelletto Cervo (Vercelli, Italy) } & TLO_M & Mortar & OSL & SAR & 46 & $822 \pm 55$ \\
\hline & TL0_B & Brick & $\mathrm{TL}$ & Added dose & 48 & $794 \pm 65$ \\
\hline & TL5_M & Mortar & OSL & SAR & 48 & $602 \pm 36$ \\
\hline & TL5_B & Brick & $\mathrm{TL}$ & Added dose & 48 & $650 \pm 40$ \\
\hline & TLOSL_B1 & Brick & TL & Added dose & 48 & $885 \pm 68$ \\
\hline & TLOSL_M & Mortar & OSL & SAR & 44 & $502 \pm 26$ \\
\hline & TLOSL_B2 & Brick & $\mathrm{TL}$ & Added dose & 48 & $931 \pm 65$ \\
\hline \multirow{5}{*}{ San Francesco alla Collina (Paternò, Italy) } & MPA7 & Mortar & OSL & SAR & 60 & $982 \pm 63$ \\
\hline & BPA7 & Brick & $\mathrm{TL}$ & Added dose & 48 & $1018 \pm 83$ \\
\hline & & & & & & \\
\hline & MPA8 & Mortar & OSL & SAR & 69 & $1008 \pm 79$ \\
\hline & BPA8 & Brick & $\mathrm{TL}$ & Added dose & 48 & $961 \pm 54$ \\
\hline \multirow{3}{*}{ Notre Dame de La Place (Bordeaux, France) } & NDLP_B1 & Brick & TL & Added dose & 48 & $1365 \pm 116$ \\
\hline & NDLP_M & Mortar & OSL & SAR & 46 & $1346 \pm 172$ \\
\hline & NDLP_B2 & Brick & $\mathrm{TL}$ & Added dose & 48 & $1348 \pm 91$ \\
\hline
\end{tabular}

*Age for mortars obtained applying Central Age Model (CAM) 
and TL5 M) and coeval to the bricks. Considering the sampling points, in fact, from historical sources (Destefanis, 2009) it is known that the bell tower is similar to the same phase of the first architectural plant, whose chronology is anchored to the end of the 1th century, or, at the latest, by the first decades of the 12th century.

The data obtained for the two bricks, even if in good agreement with the historical reference data, are certainly affected by the presence of the mortar used for the restoration. In these cases the presence of new elements introduces a further error source in determining the age due to environmental dose rate changes that receives the analyzed sample. In the particular case, most likely this effect is minimized by thin thickness of mortar and from a homogeneous gamma dose distribution in the environment.

\section{CONCLUSIONS}

The results obtained confirm the possibility of dating the lime mortar layer from historical buildings, using the OSL emission of its fine-grained fraction enriched in quartz. The cross-dating based on bricks and associated mortar samples age, if related to other data, is furthermore a way to solve chronological issues regarding historical buildings and represents a valuable improvement with respect to using the only thermoluminescence dating on bricks.

From the methodological point of view, the possibility to use polymineral fine grain phases enriched in quartz from mortars, trough etching procedure during the preparation phase must be coupled with a careful examination of several tests (e.g. preheating and recovery tests, radioactive equilibrium). It is in fact necessary to study the effects of thermal transfer that, if not considered, may lead to an overestimation of the equivalent dose. This is achieved thanks to the luminescent linear behaviour $v s$. dose of samples that allows an accurate analysis of the phenomenon. Additionally, the luminescence measurements performed on fine grain fraction, partially solve the problem of the low intensity of the luminescent signals, arising from single grains, that makes difficult the analysis.

Thus, the condition of well-bleached population identified by ED frequency Gaussian distributions and therefore the appropriate Age Model used (CAM), allowed us to obtain OSL ages for mortars, validated also from good agreement with those of associated bricks obtained through routine thermoluminescence measurements.

\section{REFERENCES}

Agersnap Larsen N, Bulu E, Bøtter-Jensen L and McKeever SWS, 2000. Use of the LM-OSL technique for the detection of partial bleaching in quartz. Radiation Measurements 32(5-6): 419-425, DOI 10.1016/S1350-4487(00)00071-8.

Aitken MJ, 1985. Thermoluminescence dating. Academic Press, London.
Bailiff IK and Holland N, 2000. Dating bricks of the last two millennia from Newcastle upon Tyne: a preliminary study. Radiation Measurements 32(5-6): 615-619, DOI 10.1016/S1350-4487(99)002863.

Bøtter-Jensen L, 1997. Luminescence techniques: instrumentation and methods. Radiation Measurements 27(5-6): 749-768, DOI 10.1016/S1350-4487(97)00206-0.

Bøtter-Jensen L, Bulur E, Duller GAT and Murray AS, 2000a. Advances in luminescence instrument systems. Radiation Measurements 32(5-6): 523-528, DOI 10.1016/S1350-4487(00)00039-1.

Bøtter-Jensen L, Solongo S, Murray AS, Banerjee D and Jungner H, $2000 \mathrm{~b}$. Using the OSL single-aliquot regenerative-dose protocol with quartz extracted from building materials in retrospective dosimetry. Radiation Measurements 32(5-6): 841-845, DOI 10.1016/S1350-4487(99)00278-4.

Choi JH, Murray AS, Jain M, Cheong CS and Chang HW, 2003. Luminescence dating of well-sorted marine terrace sediments on the southeastern coast of Korea. Quaternary Science Reviews 22(2-4): 407-421, DOI 10.1016/S0277-3791(02)00136-1.

Destefanis E, 2009. Contributo alla storia del Monachesimo Cluniacense nell'Italia Settentrionale: indagini archeologiche al Priorato di Castelletto Cervo (BI). Proceedings of the $\mathrm{V}$ Congresso Nazionale di Archeologia Medievale: 492-497.

Feathers JK, Johnson J and Kembel SR, 2008. Luminescence Dating of Monumental Stone Architecture at Chavín De Huántar, Perú. Journal of Archaeological Method and Theory 15(3): 266-296, DOI 10.1007/s10816-008-9053-9.

Galbraith RF, Roberts RG, Laslett GM, Yoshida H and Olley JM, 1999. Optical dating of single and multiple grains of quartz form Jinmium Rock Shelter, northern Australia: Part I, experimental design and statistical models. Archaeometry 41(2): 339-364, DOI 10.1111/j.1475-4754.1999.tb00987.x.

Goedicke C, 2003. Dating historical calcite mortar by blue OSL: results from known age samples. Radiation Measurements 37(4-5): 409415, DOI 10.1016/S1350-4487(03)00010-6.

Goedicke C, 2011. Dating mortar by optically stimulated luminescence: a feasibility study. Geochronometria 38(1): 42-49, DOI 10.2478/s13386-011-0002-0.

Gueli AM, Stella G, Troja SO, Burrafato G, Fontana D, Ristuccia GM and Zuccarello AR, 2010. Historical buildings: Luminescence dating of fine grains from bricks and mortar. Il Nuovo Cimento B 125: N. 5-6.

Gueli AM., Stella G, Troja SO, Burrafato G, Margani G and Zuccarello AR, 2009. Absolute dating of the Cuba of Santa Domenica (Messina, Italy). Il Nuovo Cimento B 124: 885-891.

Guérin G, Mercier N, Adamiec G, 2011. Dose-rate conversion factors: update. Ancient TL 29: 5-8.

Guibert P, Bailiff IK, Blain S, Gueli AM, Martini M, Sibilia E, Stella G and Troja SO, 2009. Luminescence dating of architectural ceramics from an early medieval abbey: The St Philbert Intercomparison (Loire Atlantique, France). Radiation Measurements 44(5-6): 488493, DOI 10.1016/j.radmeas.2009.06.006.

Kiyak NG and Canel T, 2006. Equivalent dose in quartz from young samples using the SAR protocol and the effect of preheat temperature. Radiation Measurements 41(7-8): 917-922, DOI 10.1016/j.radmeas.2006.04.006.

Mauz B and Lang A, 2004. Removal of the feldspar-derived luminescence component from polymineral fine silt samples for optical dating applications: evaluation of chemical treatment protocols and quality control procedures. Ancient TL 22: 1-8.

Murray AS and Clemmensen LB, 2001. Luminescence dating of Holocene aeolian sand movement, Thy, Denmark. Quaternary Science Reviews 20(5-9): 751-754, DOI 10.1016/S0277-3791(00)00061-5.

Murray AS and Olley J, 2002. Precision and accuracy in the optically stimulated luminescence dating of sedimentary. Geochronometria 21: 1-16.

Murray AS and Wintle AG, 2003. The single aliquot regenerative dose protocol: potential for improvements in reliability. Radiation Measurements 37(4-5): $\quad 377-381, \quad$ DOI $\quad 10.1016 / \mathrm{S} 1350$ 4487(03)00053-2. 
Olley J, Caitcheon G and Murray A, 1998. The distribution of apparent dose as determined by optically stimulated luminescence in small aliquots of fluvial quartz: implications for dating young sediments. Quaternary Science Reviews 17(11): 1033-1040, DOI 10.1016/S0277-3791(97)00090-5.

Prasad S, 2000. HF treatment for the isolation of fine grain quartz for luminescence dating. Ancient TL 18: 15-17.

Prescott JR and Hutton JT, 1988. Cosmic ray and gamma ray dose dosimetry for TL and ESR. Nuclear Tracks and Radiation Measurements 14(1-2): 223-227 DOI 10.1016/1359-0189(88)90069-6.

Ramzaev V, Bøtter-Jensen L, Thomsen KJ, Andersson KG and Murray AS, 2008. An assessment of cumulative external doses from Chernobyl fallout for a forested area in Russia using the optically stimulated luminescence from quartz inclusions in bricks. Journal of Environmental Radioactivity 99(7): 1154-1164, DOI 10.1016/j.jenvrad.2008.01.014.

Rhodes EJ, 2000. Observations of thermal transfer OSL signals in glaciogenic quartz. Radiation Measurements 32(5-6): 595-602, DOI 10.1016/S1350-4487(00)00125-6.

Saini HS and Mujtaba SAI, 2010. Luminescence dating of the sediments from a buried channel loop in Fatehabad Area, Haryana: insight into Vedic Saraswati River and its environment. Geochronometria
37: 29-35, DOI 10.2478/v10003-010-0021-5.

Shen Z, Mauz B, Lang A, Bloemendal J and Dearing J, 2007. Optical dating of Holocene lake sediments: Elimination of the feldspar component in fine silt quartz samples. Quaternary Geochronology 2(1-4): 150-154, DOI 10.1016/j.quageo.2006.03.016.

Thomas PJ, Murray AS and Sandgren P, 2003. Age limit and age underestimation using different OSL signals from lacustrine quartz and polymineral fine grains. Quaternary Science Reviews 22(1013): 1139-1143, DOI 10.1016/S0277-3791(03)00045-3.

Vermeesch P, 2009. RadialPlotter: A Java application for fission track, luminescence and other radial plots. Radiation Measurements 44(4): 409-410, DOI 10.1016/j.radmeas.2009.05.003.

Wallinga J, Murray AS, Duller GAT and Törnqvist TE, 2001. Testing optically stimulated luminescence dating of sand sized quartz and feldspar from fluvial deposits. Earth and Planetary Science Letters 193(3-4): 617-630, DOI 10.1016/S0012-821X(01)00526-X.

Zacharias N, Mauz B and Michael CT, 2002. Luminescence quartz dating of lime mortars. A first research approach. Radiation Protection Dosimetry 101(1): 379-382.

Zhang JF and Zhou LP, 2007. Optimization of the 'double SAR' procedure for polymineral fine grains. Radiation Measurements 42(9): 1475-1482, DOI 10.1016/j.radmeas.2007.06.007. 